\title{
PROFIT EXPECTATIONS AND PERCEPTION ON POTENTIAL BENEFITS OF THE ENTREPRENEURS SELECTED IN BUSINESS ACCELERATORS PROGRAMS
}

\author{
Ramona SIMUT, ${ }^{a^{*}}$, Daniel B $\breve{A D U L E S C U}{ }^{b}$, Alina B $\breve{A D U L E S C U}{ }^{c}$ \\ ${ }^{a, b, c}$ University of Oradea, Romania
}

\begin{abstract}
The importance of entrepreneurship and the dynamics of the SMEs sector upon economic growth, innovation, employment, decreasing regional disparities is undeniable, but all these effects are neither inevitable nor easily attainable. Thus, decision makers, researchers and the entrepreneurs themselves are committed to promoting and supporting the creation of new businesses as a means to stimulate and encourage development, and for this purpose, business and start-up accelerators, business incubators and/or business angels act as good case examples. By encouraging valuable business ideas, by easing the transition that exists between the moment of generating an idea to actually setting up a business and then supporting its rapid growth can be a viable means for realizing the ambitions and performances of new companies and, implicitly, for ensuring economic growth, general and individual prosperity. In this paper, by using the results and information from a survey applied to a considerable number of start-ups around the world and made available by the Entrepreneurship Database Program (EDP), we have attempted to identify the existence of a correlation between the profit margin aspirations and the potential benefits that are typically associated with entrepreneurial accelerators. Our results show that there are certain expectations regarding the usefulness and utility of entering acceleration programs and that these expectations may be correlated to the ambitions of future performances/activities. In the same time, there is a certain misalignment between how the image of entrepreneurial success is perceived, the demands and requirements of accelerator programs and the expectations of young entrepreneurs.
\end{abstract}

KEYWORDS: business accelerators, entrepreneurship, profit margin, SMEs.

\section{DOI: 10.24818/IMC/2021/03.03}

\section{INTRODUCTION}

For some time now, researchers and practitioners alike have agreed that an entrepreneurial activity is vital for the world's economies and for personal prosperity, but in the same time, it also acts as a factor of the development, mitigating regional disparities; as an agent of the continuous adaptation of economies to change and dynamism of modern-day society (McDougall et al., 1992; Reynolds et al., 2005; Haltiwanger et al., 2013). Thus, the understanding of the aspirations and objectives of a company, the understating of what it actually means to be "successful" and to achieve set and proposed ambitions, both in the medium and long term, become valuable topics for the economic literature. Even so, the field of entrepreneurship, and, more specifically, the field of SMEs in the early stages of life (so-called start-ups), seems to pose and be faced by additional problems, even if the research area is much narrower, both from a temporal but also in complexity point of view. In other words, we must accept that the indicators, criteria and objectives used in this specific field can change rapidly as opposed to those used in the already consolidated business areas.

\footnotetext{
${ }^{*}$ Corresponding author. E-mail address: simut.ramona@yahoo.com
} 
In our specific case, we are interested in finding out how a company/an entrepreneur reconciles the expectations of the (ever-so-often over-optimistic) business performance with the reality of the early stages of a start-up, in which survival is imperatively necessary. In the same time, we are aware that just the simple setting of quantitative goals (e.g. the setting of certain turnover levels, profit margins, or market share) and even the appreciation and awareness from the community and/or professional networks, is not synonymous with the image of entrepreneurial success. Moreover, the launch of a business and setting of goals (optimistic or even realistic ones) is not equivalent to actually achieving them, as a majority of small and medium firms enter and leave the market with a small or negligible contribution (Badulescu, 2013), and the survival rate of small and medium firms is quite small even in the most developed economies (Eurostat, 2016; Small Business Administration (SBA), 2015). Consequently, only a small number of firms and are able to maintain a high growth rate (Haltiwanger et al., 2013; Rogers, 2009). However, academics and policy maker are aware that a "natural selection" that would result in leaving only legitimately performing companies to function would mean a considerable waste of human resources and capital, of energies and innovations. This is probably the reason for which many actions and strategies, be them public or private, such as business-angel networks, incubators or business accelerators, try to encourage and support business initiatives, in order to identify potentially successful projects and initiatives (especially in their early stages).

Throughout this current paper, we have tried to provide an answer to the following question: to what extent are the objectives of achieving a certain profitability associated to the expected benefits as a result of entering in certain business accelerator programs? To provide this question with an answer, have used the results of a survey involving a large number of new ventures belonging to entrepreneurs from all over the world, enrolled in various business accelerator programs. Thus, the paper is structured as follows: we start off with an introduction on the context and motivations of our research and following, we continue with a review of international literature on subject of business objectives, performance and their relation with entrepreneurial success, as well as several features regarding the role of accelerators and incubators as regards the stimulating of entrepreneurial achievement and firm growth. After this section, our focus concern research methodology, analysis and the interpretation of the results. In the end, we have drawn conclusions and offered several recommendations on economic policies, have stated the limitations of our study and possible research directions.

\section{BUSINESS PERFORMANCE ASSESSMENT AND ENTREPRENEURIAL SUCCESS}

What are the objectives of a new business and how are they corelate to the concept of accomplishment and of business success? The process of formally setting, stating and establishing the objectives of a business, in itself, is not a very complicated process, instead, the real challenge and difficulty lies in the pairing of the real possibilities to the proposed levels of performance, both in the minds of the entrepreneurs, but also of the researchers concerned with this particular topic.

Newly formed or young firms do not have historical information; what is more, they do not operate with standardized accounting techniques and nor do they fully rely and fully report themselves to performance indicators. The lack of profit (or the existence of a small profit, a profit which is practically meaningless and irrelevant) in the first years of operating is not an unusual situation, even if the respective companies have an increasing turnover (sales) (Brush \& Vanderwerf, 1992; McDougall et al., 1992; Santarelli \& Vivarelli, 2007; Badulescu et al., 2019).

Moreover, the founder of a business, although motivated by great ambitions, has neither the time nor does he have the most suitable qualifications and experiences in order to produce a realistic assessment of the business and to report and relate it to attainable targets. In many cases, founders report and compare themselves to very high thresholds (considered either motivating or inspiring) or, prudently, declare themselves as being satisfied with the current, even though limited, survival 
levels, whilst waiting for an opportunity to arise. In many cases, even though the survival and the gaining of a certain a market position in the early years seems to suggest a successful venture, this seeming success is characterized by instability, high costs and lack of managerial experience. For this reason, a number of researchers have looked in a somewhat cautious manner at the excessive use of financial performance indicators (Hillman \& Keim, 2001), and have elected to favoured the use of such elements as competitive position, market penetration, the behaviour and relationship with competitors. Several studies show that, in the early stages of life, the success of a company is, in fact, synonymous with survival, or in other words, the main objective of the company is to survive and then set forth ambitious goals for increasing the turnover, profit margins etc. (Bosma et al., 2004; Santarelli \& Vivarelli, 2007). Explicitly, survival refers to creating the propped conditions in order for the business launch to take place, and this "resistance" is what differentiates persistent entrepreneurs from those that give up, and survival, as an "indicator", is effortless to identify and measure.

Objectively, financial indicators have been, and are still considered by a large portion of researchers, practitioners, managers and, last but not least, by entrepreneurs, as the most reliable criteria for measuring the performance of a company, and is to be considered as being a numerical expression for the success and economic performance of a company (Murphy et al., 1996; Zahra \& Covin, 1995; Katabi \& Dimoso, 2016).

Even so, the fact that the business sectors tend to be different from one another, that innovation and technology require rapid rates of change, that there are many difficulties in comparing the profitability of different start-ups in the first years of the company's life (Bosma et al., 2004). Thus, Stuart and Abetti (1987) have proposed a broader concept of performance that includes economic but non-financial indicators, such as market share, business sustainability (Newby et al., 2012; Badulescu et al., 2015); the introduction of new products and services, increasing the quality (McGee et al., 1995; Gruber et al., 2010). Thus, without surrendering from the principle of comparing objective indicators, it is accepted that the success of a newly created companies is difficult to measure by only using only conventional financial indicators (Hart et al., 1995; Birley \& Westhead, 1994), thus increasing the role and importance of innovation (Usoff et al., 2002; Kaplan $\&$ Norton, 1992), of the human and "entrepreneurial" capital, and the importance of intangible assets as key factors for the attaining of success (Audretsch \& Keilbach, 2004).

Researchers are constantly attempting to find criteria that are suitable for measuring to the special nature of young firms, even if these methods depart from the conventional measures commonly used by large corporations or already consolidated businesses. Even so, Pérez and Canino (2009) gather and enlist information from literature and have found that even in the case of small, young companies, the indicators most commonly used to reflect the performance and success of new companies were those related to the growth of the company ( $31 \%$ of cases), followed by profitability indicators (over 18\% from cases), profit (almost 14\%) and liquidity (with 7\%). Interestingly, indicators such as employee income levels, human capital improvement, cohesion of the organization and the team, novelty of processes and products/services, customer satisfaction, dominance of competition, do not exceed $25 \%$ of the total, many having individual scores of less than $3-4 \%$.

According to Pérez \& Canino (2009) studies that use subjective measures in order to assess the company's performance and success have increased in importance in recent decades, counterbalancing the excessive use and dominance of objective, financial measures. Moreover, numerous opinions consider that, unlike large, consolidated firms, with a significant business background, history and where quantitative methods are more appropriate, in the case of small, young firms, subjective measures are more appropriate (Wang \& Ang, 2004). Secondly, financialaccounting information in the case of young or newly formed companies is low and difficult to interpret. Finally, the characteristics pertaining to the specificity of each sector of activity can seriously make it difficult to compare the data of and from start-ups. The optimism of promoting the 
subjective methods of appreciating the performance and the success of newly formed businesses must, however, be tempered - it is difficult to make them operational precisely because of this subjective component, their lack of precision and the different points of view of different entrepreneurs and, not infrequently, of the researchers. A middle ground, a combination of objective and subjective techniques seems more appropriate when measuring new business performance. Mixing of the two approaches could lead to the fulfilling of the requirements for integrating objective measures with subjective expectations and further completing the understanding of entrepreneurial ambitions.

\section{BUSINESS ACCELERATORS AND GROWTH OBJECTIVES OF SMES}

During the last several decades, we have witnessed the rebirth of the entrepreneurial spirit, the establishment and setting up of new companies, the ever so increasing importance of innovation and the opportunities brought by the digital world. Alongside, we are also witnessing a reform as regards the entrepreneurial ecosystem, and more precisely regarding the support structures of the incipient businesses with high growth potential; some of the actors of the new economic reality, are without a doubt, the business accelerators together with angel investors and business incubators networks, cooperation spaces or hybrid systems (Cohen, 2013; European Union/OECD, 2019). Some estimates imply that accelerators play an increasingly important role in the launch of new high potential businesses, but that they also play an important role as regards consolidated businesses (Cohen, 2013; Dempwol et al., 2014; Cohen et al., 2109; Hathaway, 2016). Initially associated with the dynamism and focus on high-tech industries specific to the United States of America, the network of business accelerators has gradually expanded worldwide, expressing their significant potential to improve start-up results and disseminate these benefits and best practices among other businesses and communities as a whole.

The main objective of business accelerators is that of supporting new business, from the early stages of conception and launch, all the way to preparing new business for rapid growth. They do this through an array and group of professional services, education, mentoring, and financing in a competitive program format, the selected companies being introduced in this process for a relatively short period of time, and usually as part of a group of companies (Hathaway, 2016). For entrepreneurs, the experienced gained by being part of an accelerator is unique (Dempwol et al., 2014) - it is an intense, fast-paced and captivating education process aimed at accelerating the life cycle of young, innovative companies, aimed at practically learning and acquiring information that would normally take years to learn, in just a few months. These unique elements (duration, involved individuals, mentoring and graduation) are specific to accelerators and allow us to differentiate them from other support measures and tools, even if the main objective is similar: cultivating, at an early stage, the growth potential of start-ups (Cohen, 2013; Cohen et al., 2019).

Although research aimed on the activity and effects of accelerators on young business is not very numerous and has not reached a consensus among researches and entrepreneurs on most concepts, there is a relatively general acceptance in identifying some effects (Hathaway, 2016), that influence customer market, activities, rewards, value experience, and alternatives and sources of and for differentiation (Dempwol et al., 2014). First and foremost, the research on comparable groups of companies that were selected in acceleration programs and, respectively, that were not selected, has found that those who graduated from the top accelerator programs registered an increased rate of reaching some key individual goals, such as obtaining the necessary funding, exit by acquisition, and gaining customer trust and recognition (Hathaway, 2016). Nonetheless, these positive effects are not as obvious when being compared within selected groups or when looking for averages on a larger group of accelerators. In other words, we can either have inadequate accelerators or inadequate selection programs (at times both) that do not manage to aid, assist or help new entrants to grow. Another analysis on comparable groups of firms (accelerated vs. non-accelerated) indicates 
that both the learning effects and the experience gained in regards to the relationship with potential investors is invaluable.

Firms/entrepreneurs who have successfully graduated from an accelerator program always had much better chances of receive financing (either a classic type of financing or financing coming from various business angels) even during the next stages of company growth, even though they were no longer in the respective accelerator. Moreover, these chances do not only refer to receiving the desired amount, but also to the most favourable financing conditions and the speed of receiving the desired amount. Another important result and conclusion of the study of accelerators it is that they better prepare entrepreneurs and manage to provide them with experiences and insights vital for the future business stages, in order to capitalize on opportunities, but also to survive in times of crisis. Finally, accelerators have a positive impact on regional and local entrepreneurial ecosystems, especially in terms of stimulating funding and creating adequate funding sub-structures, increased technology transfer and job creation (European Union/OECD, 2019). Even if these effects initially mainly benefit the big and already consolidated urban business centers, gradually, the spillover effect will generate beneficial impacts for other peripheral business structures, which can benefit from improvements made to the lending environment, even if they were not included in acceleration programs or the like. In other words, the positive effects are not only limited to encouraging the growth of small companies, newly founded or consolidated, but also among investors and creditors. In a research undertaken and conducted by I-DEV International, together with the Aspen Network of Development Entrepreneurs (ANDE) and Agora Partnerships (2014), these organizations have set out to determine the impact of the activity conducted by business accelerators, incubators and to research and find out the value created for social enterprises by selected by investors. The most obvious finding is that small growth (oriented) businesses (SGB), during early development stages, find greater money-value in incubators/accelerators than SGB during growth stages, but they are also quite discouraged by raised capital and investment readiness support.

The analysis of the physical growth of the companies (regardless of their stage of development) was relatively moderate in terms of number of employees, but somewhat encouraging in terms of turnover (more evident for companies which are in the early stages of growth). Only $50 \%$ of the growing companies considered that the incubator/accelerator programs have in fact aided them so as to better understand and capitalize on the relations and meetings with the various investors and lenders. This may be a clear indication as to the inadequate alignment between investors, growth companies and the objectives of incubators/accelerators.

\section{RESEARCH METHODOLOGY}

Our research is based on data series made available by the Entrepreneurship Database Program (EDP), housed at Emory University, which includes application data collected from programs that opened applications during the 2013-2017 window; in the same time, included information also consists of the first year of follow-up data, from entrepreneurs who applied to a self-selected group of accelerator programs. The Entrepreneurship Database Program at Emory University has date which is interrelated to a wide range of accelerator programs, in order to systematically collect data from entrepreneurs who apply to and, if selected, participate in these programs. This vast, prospective, data collection program is part of the Global Accelerator Learning Initiative/GALI (Entrepreneurship Database Program \& Aspen Networks of Development Entrepreneurs (EDP), 2019).

The main data and the synthetic information we have used is contained in the 2018 Report, which includes the analysis of 13,845 responses given by entrepreneurs who have applied for accelerator programs that started in 2013. We have selected 11,776 for-profit companies who applied for the EDP accelerator programs. In this research have tried to find out whether there is a correlation between the profit margin aspirations expressed by entrepreneurs and the potential benefits that are typically associated with entrepreneurial accelerators. 


\section{RESULTS AND DISCUSSIONS}

Table 1 outlines the structure of companies by the potential benefits that are typically associated with entrepreneurial accelerators. The companies have ranked these benefits in terms of "how important they are the development and success of their venture", by using the Likert scale, where 1 is the most important and 7 is the least important.

Table 1. The importance of the potential benefit from accelerator programs

\begin{tabular}{|l|c|c|c|c|c|c|c|c|c|}
\hline $\begin{array}{l}\text { Benefits from } \\
\text { accelerator } \\
\text { programs }\end{array}$ & $\begin{array}{c}\text { Average } \\
\text { Rank }\end{array}$ & Median & Mode & $\begin{array}{c}\text { Std. } \\
\text { Dev }\end{array}$ & Skewness & Kurtosis & Min & Max & N \\
\hline $\begin{array}{l}\text { Network } \\
\text { development }\end{array}$ & 3.31 & 3 & 1 & 1.912 & 0.379 & -0.996 & 1 & 7 & 11776 \\
\hline $\begin{array}{l}\text { Business skills } \\
\text { development }\end{array}$ & 3.95 & 4 & 2 & 1.977 & 0.027 & -1.231 & 1 & 7 & 11776 \\
\hline $\begin{array}{l}\text { Mentorship from } \\
\text { business experts }\end{array}$ & 3.48 & 3 & 3 & 1.768 & 0.242 & -0.949 & 1 & 7 & 11776 \\
\hline $\begin{array}{l}\text { Access and } \\
\text { connections to } \\
\text { potential } \\
\text { investors/funders }\end{array}$ & 3.52 & 3 & 2 & 1.746 & 0.338 & -0.912 & 1 & 7 & 11776 \\
\hline $\begin{array}{l}\text { Securing direct } \\
\text { venture funding }\end{array}$ & 3.57 & 3 & 1 & 2.037 & 0.234 & -1.246 & 1 & 7 & 11776 \\
\hline $\begin{array}{l}\text { Gaining access } \\
\text { to a group of } \\
\text { like-minded } \\
\text { entrepreneurs }\end{array}$ & 5.1 & 6 & 6 & 1.727 & -0.767 & -0.394 & 1 & 7 & 11776 \\
\hline $\begin{array}{l}\text { Awareness and } \\
\text { credibility }\end{array}$ & 5.07 & 6 & 7 & 1.903 & -0.671 & -0.745 & 1 & 7 & 11776 \\
\hline
\end{tabular}

Note: Std.Dev. - standard deviation, Min - minimum value, Max - maximum value, $\mathrm{N}$ - sample volume. Question: "The following are some of the potential benefits that are typically associated with entrepreneurial accelerators. Please rank these benefits in terms of how important they are to your venture's development and success (1 - the most important and 7 - the least important)." Source: The Entrepreneurship Database Program at Emory University

According to the results presented in Table 1, we can say that the sampled entrepreneurs give a very high importance, over $22 \%$, to the potential benefits of network (network development) and securing direct venture funding (e.g. grants or investments). Also, entrepreneurs give a relatively high importance to the connections to potential investors/funders, business skills development and mentoring. On the other hand, "gaining access to a group of like-minded entrepreneurs" and "awareness and credibility" are the least important of the seven potential benefits. 


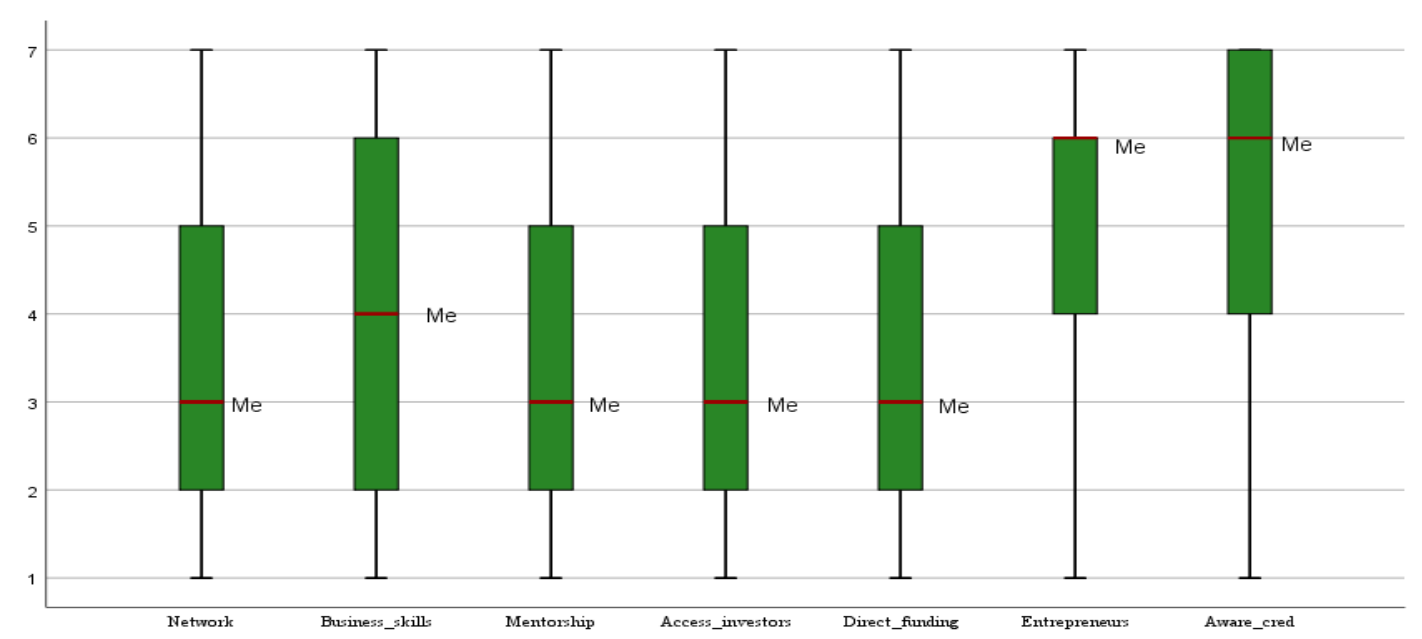

Figure 1. Boxplot of the importance of the potential benefit (Likert scale analysis) Source: The Entrepreneurship Database Program at Emory University

Figure 1 presents a similar summary across the importance of the potential benefits arising from taking part in accelerator programs that are typically associated with entrepreneurial accelerators. On the boxplot we have: the horizontal lines that represent the minimum value and the maximum value, the red line which represents the median, whilst the outer boundary of the boxes indicates the first and third quartile. The results show that most entrepreneurs consider network development, mentorship, the connections to potential investors and securing direct venture funding as quite an important potential benefit (low median with wide range). Instead, they consider gaining access to a group of like-minded entrepreneurs and the awareness and credibility as less important (high median with wide range). Based on these results, we want to determine how the average rank of the importance of these potential benefits is influenced by the profit expected by the entrepreneurs.

In order to understand the profit margin expected by the entrepreneurs, we considered six different target margins (no specific target, 0\%-5\%,6\%-10\%, 11\%-15\%, 16\%-20\%, more than 20\%) based on the following question "What annual profit-margins would you be happy with achieving on average?".

Table 2. The average rank of the importance of the potential benefit depending on the profit margin

\begin{tabular}{|l|c|c|c|c|c|c|c|c|}
\hline \multirow{2}{*}{$\begin{array}{c}\text { Profit } \\
\text { margin } \\
\text { (for-profit } \\
\text { ventures) }\end{array}$} & \multirow{2}{*}{$\mathrm{N}_{\mathrm{i}}$} & \multicolumn{7}{|c|}{ Benefits from accelerator programs } \\
\cline { 3 - 9 } & & Network & $\begin{array}{c}\text { Business } \\
\text { skills }\end{array}$ & $\begin{array}{c}\text { Mentor } \\
\text { ship }\end{array}$ & Investors & $\begin{array}{c}\text { Direct } \\
\text { funding }\end{array}$ & Entrepreneurs & Awareness \\
\cline { 3 - 9 } & \multicolumn{7}{|c|}{ Average Rank } \\
\hline $\begin{array}{l}\text { No specific } \\
\text { target }\end{array}$ & 3878 & 3.30 & 3.99 & 3.43 & 3.58 & 3.64 & 5.07 & 5.00 \\
\hline $0 \%-5 \%$ & 149 & 3.37 & 3.95 & 3.68 & 3.49 & 3.62 & 4.91 & 4.97 \\
\hline $11 \%-15 \%$ & 950 & 3.38 & 3.90 & 3.48 & 3.44 & 3.62 & 5.06 & 5.12 \\
\hline $16 \%-20 \%$ & 1697 & 3.34 & 3.97 & 3.37 & 3.44 & 3.51 & 5.12 & 5.24 \\
\hline $6 \%-10 \%$ & 592 & 3.33 & 3.77 & 3.46 & 3.58 & 3.60 & 5.07 & 5.17 \\
\hline $\begin{array}{l}\text { More than } \\
20 \%\end{array}$ & 4510 & 3.30 & 3.98 & 3.54 & 3.47 & 3.52 & 5.13 & 5.06 \\
\hline Total & $\mathbf{1 1 7 7 6}$ & $\mathbf{3 . 3 1}$ & $\mathbf{3 . 9 5}$ & $\mathbf{3 . 4 8}$ & $\mathbf{3 . 5 2}$ & $\mathbf{3 . 5 7}$ & $\mathbf{5 . 1 0}$ & $\mathbf{5 . 0 7}$ \\
\hline
\end{tabular}

Note: $\mathrm{N}_{\mathrm{i}}-$ absolute frequencies.

Source: The Entrepreneurship Database Program at Emory University 
Considering the for-profit ventures, the largest groups are comprised of ventures that seek profit margins in excess of 38 percent $(\mathrm{N}=4,510)$. The ventures with the highest margin objectives and those with no specific target, on average, consider the networking benefits as one of the most important potential benefits (average rank $=3.3$ ) and gaining access to a group of like-minded entrepreneurs as one of the least important potential benefits. Regarding the other profit margins objectives (0-10\%), we observe that networking benefits remains the most important potential benefit followed by the access and connections to potential investors/funders, and also by the mentorship from business experts. Entrepreneurs whose profit objective is between 0 and 10\% give very little importance to awareness and credibility (e.g., association with a recognized program, press/media exposure). Thus, network development (e.g., with potential partners and customers) is considered as being the most important potential benefit that is typically associated with entrepreneurial accelerators. This network development can be useful to entrepreneurs, given that they can grow the level of credibility and visibility of their company, and because network development can provide resources that would not be available at all in market, such as reputation, contacts with customers and suppliers.

Also, in this study we want to find whether there is a correlation between the profit margin aspirations expressed by entrepreneurs and the potential benefits that are typically associated with entrepreneurial accelerators. The most used parametric test used in order to determine the association between two variables is the Pearson correlation, whilst in the case of nonparametric tests we have Spearman rank correlation coefficient that was first studied by Spearman (1904) and Kendall's Tau coefficient proposed by Kendall (1938), these being two of the most known nonparametric tests. Given that in this study we have six variables that are measured on a scale that is ordinal, we cannot use the Pearson correlation, and therefore we will use the Spearman Rank Correlation Coefficient and Kendall's Tau coefficient.

Table 3. Correlation between the profit margin and the potential benefits from accelerator programs

\begin{tabular}{|l|c|c|}
\hline & \multicolumn{2}{|c|}{ Profit margin } \\
\hline Benefits from accelerator programs & Spearman's rho & Kendall's tau \\
\hline \multirow{2}{*}{ Network development } & -0.001 & -0.001 \\
& $(0.909)$ & $(0.909)$ \\
\hline \multirow{2}{*}{ Business skills development } & -0.003 & -0.002 \\
& $(0.733)$ & $(0.737)$ \\
\hline \multirow{2}{*}{ Mentorship from business experts } & $-0.028^{* * * *}$ & $-0.023^{* * *}$ \\
Access and connections to potential & $(0.002)$ & $(0.002)$ \\
investors/funders & $-0.025^{* * * *}$ & $-0.020^{* * *}$ \\
\hline \multirow{2}{*}{ Securing direct venture funding } & $(0.007)$ & $(0.007)$ \\
\hline Gaining access to a group of like-minded & $-0.025^{* * * *}$ & $-0.020^{* * *}$ \\
entrepreneurs & $(0.006)$ & $(0.006)$ \\
\hline \multirow{2}{*}{ Awareness and credibility } & $0.017^{*}$ & $0.014^{*}$ \\
& $(0.06)$ & $(0.05)$ \\
\hline
\end{tabular}

Data outside parentheses are Spearman's correlations and Kendall's tau. P-value (p) in parenthesis. $* * * \mathrm{p}<0.01$ (2-tailed). $* * \mathrm{p}<0.05$ (2-tailed). $* \mathrm{p}<0.10$ (2-tailed).

Source: Authors' calculation using the Entrepreneurship Database Program at Emory University

Spearman's rho and Kendall's Tau correlations suggest significant relationships between the profit margin objectives and some of the potential benefits that are typically associated with 
entrepreneurial accelerators in our sample. A significant correlation between the profit margin objectives and Mentorship from business experts $(p=0.002)$, profit margin objectives and access and connections to potential investors/funders $(\mathrm{p}=0.007)$, profit margin objectives and Securing direct venture funding $(\mathrm{p}=0.006)$, profit margin objectives and Gaining access to a group of likeminded entrepreneurs $(p=0.06)$ has been found. In the case of the first three potential benefits that are typically associated with entrepreneurial accelerators, we have a negative correlation. Because the scale of the potential benefits that are typically associated with entrepreneurial accelerators is from $1=$ most important to $7=$ less important, and in case of the profit margin, we have $1=0 \%-5 \%$ and $5=$ more than $20 \%$, we can conclude that the higher the profit margin objective is, the benefits such as mentoring, the connections with potential investors and also in ensuring the direct financing of the risk, are higher. Regarding the gaining of access to a group of like-minded entrepreneurs we have found a positive correlation. Therefore, we can conclude that the higher the profit margin objective is, the smaller the gaining of access to a group of like-minded entrepreneurs becomes.

\section{CONCLUSIONS}

Assessing the performance of a business and linking it to the ambitions and expectations of entrepreneurs is an essential topic for researchers, entrepreneurs and managers. In general, a business is efficient and well performing as long as it has "the operational ability to satisfy the desires of major shareholders" (Smith \& Reece, 1999), and achieves its organizational goals (Murphy et al., 1996) as most of these objectives are superimposed with those of the ownermanager (Birley \& Westhead, 1994; Brush, 1992). The analysis of literature has shown that the quantitative financial approach is only part of the methods and tools by and through which we can measure the performance of a company in relation to entrepreneurial objectives. However, their practical value and provisional possibilities make them as the preferred methods and tools used by analysts and entrepreneurs. We have found that the most used indicator used for the setting of objectives and measuring the entrepreneurial ambitions is the increase of turnover (increase of sales) followed, relatively close, by the increase of the net profit and the number of employees, and afterwards, followed by indicators such as ROA (Return on Assets), ROI (Return on Investment), ROS (Return on Sales) or ROE (Return on Equity). However, we consider that the precautions expressed by researchers who insisted that, at least during first years of business life, the financial criteria should not be the only instrument for assessing and measuring real performances and the success. The information available in the database has allowed the use of a balanced approach, in which the analysis of the correlation between the financial objectives (expressed by target margins) and, respectively, the expectations of the usefulness of the accelerators as regards continued development of businesses are sufficiently suggestive, without being sophisticated and distant from the specific realities of small companies, companies which are in the early stages of growth.

In our study, based on 11,776 for-profit companies who applied for the EDP accelerator programs, we have found that some of the potential benefits that are typically associated with entrepreneurial accelerators are those related to the network development and the securing direct venture funding. Over $22 \%$ of the entrepreneurs give a very high importance to these two potential benefits. Following these two benefits, the next that are considered as being relatively important are those associated to the connections to potential investors/funders, business skills development and mentoring. The gaining access to a group of like-minded entrepreneurs and awareness and credibility are the least important of the seven potential benefits.

We have also found that the ventures with the highest profit margin objectives and those with no specific target, on average, consider the networking benefits as one of the most important potential benefits (average rank $=3.3$ ) and gaining of access to a group of like-minded entrepreneurs as one of the less important potential benefits. In order to study the correlation between the profit margin aspirations expressed by entrepreneurs and the potential benefits that are typically associated with 
entrepreneurial accelerators, we have used Spearman's rho and Kendall's Tau correlations. The results suggest a negative and significant correlation between the profit margin objectives and mentorship from business experts $(\mathrm{p}=0.002)$, profit margin objectives and access and connections to potential investors/funders $(\mathrm{p}=0.007)$, profit margin objectives and securing direct venture funding $(\mathrm{p}=0.006)$, while between profit margin objectives and gaining access to a group of likeminded entrepreneurs $(\mathrm{p}=0.06)$ we have found a positive and significant correlation. Therefore, we can conclude that between the profit margin aspirations expressed by entrepreneurs and the potential benefits that are typically associated with entrepreneurial accelerators, there is a correlation. Thus, the higher the profit margin objective is, the higher the importance of mentorship, access and connections to potential investors/funders and securing direct venture funding is.

One of the limitations of our study refers to the reduced number of observation's years (from $2016 / 2017$ - the first selection to the acceleration program, to 2018) and the impossibility of verifying the achievement of the proposed objectives. In future researches, we propose to perform a comparative analysis using different statistical methods to determine if the relationship between expected benefits and profits is preserved.

It is difficult to predict what the future of business accelerators or, rather, the targeted areas and markets will be. However, there is a growing interest in specialization and consolidation, a gradual shift from the area of enthusiastic initiatives to a more corporate organization, in which large companies will use these accelerators to get even closer to innovative start-ups. Last but not least, it is expected that this expansion will continue both vertically (by including in these forms of support as many types of young companies as possible, not just start-ups themselves) and horizontally (spatially) - in most regions of the world, and especially in the new emerging markets with the potential for rapid growth.

\section{ACKNOWLEDGMENT}

"Data provided by the Entrepreneurship Database Program at Emory University; supported by the Global Accelerator Learning Initiative". Any interpretations or conclusions that are drawn from these data are to be attributed entirely and solely to article's authors and not to the Entrepreneurship Database Program or to the Global Accelerator Learning Initiative.

\section{REFERENCES}

Audretsch, D. \& Keilbach, M. (2004). Entrepreneurship capital and economic performance. Regional Studies, 38(8), 949-959.

Badulescu, D. (2013). Dezvoltarea și finanțarea afacerilor antreprenoriale. Particularități în turism/Development and financing of entrepreneurial business. Particularities in tourism. Cluj Napoca, Romania: Presa Universitară Clujeană.

Badulescu, D., Bungau, C. \& Badulescu, A. (2015). Sustainable development through sustainable businesses. An empirical research among master students. Journal of Environmental Protection and Ecology, 16(3), 1101-1108.

Badulescu, D., Simut, R. \& Badulescu, A. (2019). New Ventures' Objectives and Entrepreneurs' Expectations. Evidence from EDP-Surveyed Companies. Bucharest, Romania: Proceedings of the 13th International Management Conference "Management Strategies for High Performance", 31st October - 1st November, 2019.

Birley, S. \& Westhead, P. (1994). A taxonomy of business start-up reasons and their impact on firm growth and size. Journal of Business Venturing, 9(1), 7-31.

Bosma, N., Van Praag, M., Thurik, R. \& DeWit, G. (2004). The value of human and social capital investments for the business performance of startups. Small Business Economics, 23, 227-236. 
Brush, C. (1992). Research on women business owners: past trends, a new perspective and future directions. Entrepreneurship Theory and Practice, 16(4), 5-30.

Brush, C. \& Vanderwerf, P. (1992). A comparison of methods and sources for obtaining estimates of new venture performance. Journal of Business Venturing, 7(2), 157-170.

Cohen, S. (2013). What Do Accelerators Do? Insights from Incubators and Angels. Innovations: Technology, Governance, Globalization, 8(3-4), 19-25. doi:10.1162/inov_a_00184.

Cohen, S., Fehder, D., Hochberg, Y. \& Murray, F. (2019). The design of startup accelerators. Research Policy, 48(7), 1781-1797.

Dempwol, C., Auer, J. \& D'Ippolito, M. (2014). 2014, Innovation Accelerators: Defining Characteristics Among Startup Assistance Organizations. Washington, D.C., USA: Small Business Administration, Office of Advocacy.

Entrepreneurship Database Program \& Aspen Networks of Development Entrepreneurs (EDP). (2019). The Entrepreneurship Database Program at 2018 Year-End Data Summary. Emory University.

European Union/OECD. (2019). Policy Brief on Incubators and Accelerators that Support Inclusive Entrepreneurship. Luxembourg: Publications Office of the European Union.

Eurostat. (2016). Business demography by size class (from 2004 onwards, NACE Rev. 2). Retrieved May 10, 2019, from [bd_9bd_sz_cl_r2].

Gruber, M., Heinemann, F., Brettel, M. \& Hungeling, S. (2010). Configurations of resources and capabilities and their performance implications: An exploratory study on technology ventures. Strategic Management Journal, 31(12), 1337-1356.

Haltiwanger, J., Jarmin, R. \& Miranda, J. (2013). Who Creates Jobs? Small vs. Large vs. Young. Review of Economics and Statistics, 95(2), 347-361.

Hart, M., Stevensen, H. \& Dial, J. (1995). Entrepreneurship: a definition revisited. In W. Bygrave (Ed.), Frontiers of entrepreneurship 1995. Proceedings of the 15th Annual Entrepreneurship Research Conference, 75-89. Babson Park: Babson College.

Hathaway, I. (2016). What Startup Accelerators Really Do. Harvard Business Review, Retrieved from https://hbr.org/2016/03/what-startup-accelerators-really-do.

Hillman, A. \& Keim, G. (2001). Shareholder value, stakeholder management, and social issues: What's the botton line? Strategic Management Journal, 22(2), 125-140.

I-DEV International, Aspen Network of Development Entrepreneurs, Agora Partnerships. (2014). Measuring Value Created by Impact Incubators \& Accelerators. I-DEV Int. \& ANDE \& Agora Partnerships.

Kaplan, R. \& Norton, D. (1992). The balanced scorecard. Measures that drive performance. Harvard Business Review, 71-79.

Katabi, R. \& Dimoso, R. (2016). The Relationship Between Financial Goals of SMES and Investment Decisions. Journal of Business Studies Quarterly, 7(4), 78-90.

Kendall, M. (1938). A new measure of rank correlation. Biometrika, 5, 81-93.

McDougall, P., Robinson, R. \& DeNisi, A. (1992). Modeling new venture performance: An analysis of new venture strategy, industry structure, and venture origin. Journal of Business Venturing, 7, 267-289.

McGee, J., Dowling, M. \& Megginson, W. (1995). Cooperative Strategy and New Venture Performance: The Role of Business Strategy and Management Experience. Strategic Management Journal, 16(7), 565-580.

Murphy, G., Trailer, J. \& Hill, R. (1996). (1996). Measuring performance in entrepreneurship research. Journal of Business Research, 36(1), 15-23.

Newby, R., Watson, J. \& Woodliff, D. (2012). Developing an Instrument to Examine the Goals of SME Owner-Operators. Small Enterprise Research, 19(2), 74-95.

Pérez, E. \& Canino, R. (2009). The Importance of the Entrepreneur's Perception of "Success". Review of International Comparative Management, 10(5), 990-1010. 
Reynolds, P., Bosma, N., Autio, E., Hunt, S., DeBono, N., Servais, I. \& Chin, N. (2005). Global Entrepreneurship Monitor: Data Collection Design and Implementation 1998-2003. Small Business Economics, 24, 205-231.

Rogers, S. (2009). Entrepreneurial Finance. Finance and Business Strategies for the Serious Entrepreneur (Second Edition ed.). New York: McGraw-Hill Companies.

Santarelli, E. \& Vivarelli, M. (2007). Entrepreneurship and the process of firms' entry, survival and growth. Industrial and Corporate Change, 16(3), 455-488.

Small Business Administration (SBA). (2015). Survival Rates and Firm Age. Retrieved May 11, 2019, from https://www.sba.gov/sites/default/files/SurvivalRatesAndFirmAge_ADA_0_0.pdf.

Smith, T. \& Reece, J. (1999). The relationship of strategy, fit, productivity, and business performance in a services setting. Journal of Operations Management, 17(2), 145-161.

Spearman, C. (1904). The proof and measurement of association between two things. American Journal of Psychology, 15, 73-101.

Stuart, R. \& Abetti, P. (1987). Start-up ventures: towards the prediction of initial success. Journal of Business Venturing, 2, 215-230.

Usoff, C., Thibodeau, J. \& Burnaby, P. (2002). The importance of intellectual capital and its effect on performance measurement systems. Managerial Auditing Journal, 17, 9-15.

Wang, C. \& Ang, B. (2004). Determinants of venture performance in Singapore. Journal of Small Business Management, 42(4), 347-363.

Zahra, S. \& Covin, J. (1995). Contextual influences on the corporate entrepreneurship-performance relationship: A longitudinal analysis. Journal of Business Venturing, 10, 43-58. 